تطبيق طريقة التلقيح في أجنة الاجاج ضد مرض نيوكاسل ونيوكاسل وكمبورو

$$
\begin{aligned}
& \text { عبد الامير حسين زاهد نوال صالح جعفر أنطوان صبري البنأ }
\end{aligned}
$$

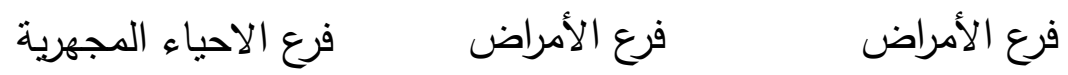

$$
\begin{aligned}
& \text { كلية الطب البيطري - جامعة بغداد }
\end{aligned}
$$

\title{
الخلاصة
}

تعد هذه الدراسة المحاولة الاولى في قطرنا العراق وذللك في تطبيق تلقيح اجنة الدجاج لحماية

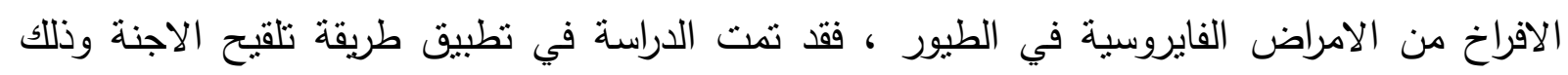

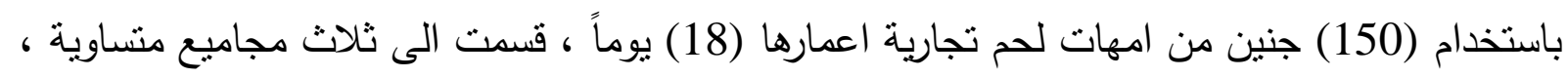

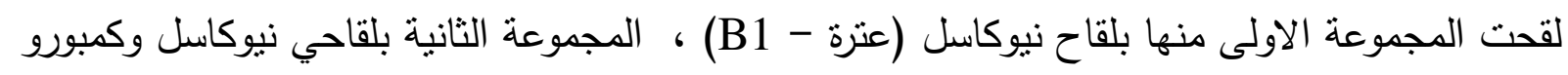
المزدوج (عترة - B1 ، وعترة - Lukert) وذللك بحقن اللقاح في كيس الامينون ، اما المجموعة الثالثة

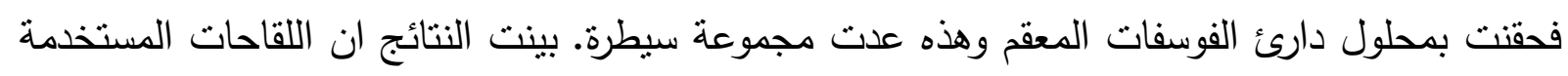
في حقن الاجنة لم تكن ذات تأثير سالب على نسبة الفقس وحيوية الافراخ. استخدم اختبار اثباط التنالن الدموي ، واختبار الاليزا ، واختبار الكتحدي وذلك لقياس المستوى المناعي للافراخ الملقحة بلقاح نيوكاسل

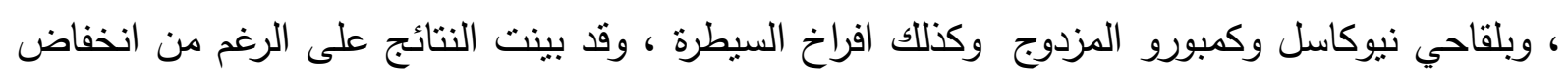

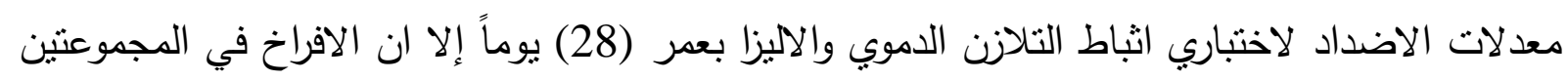

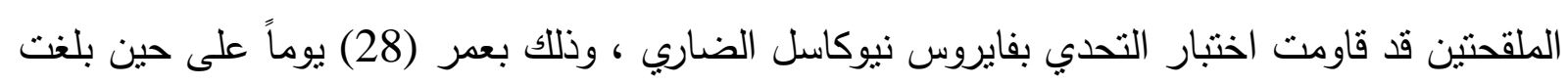

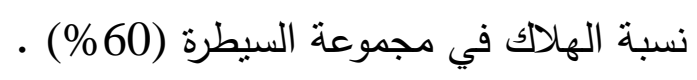

\section{Study Of Chick Embryo Vaccination Against Newcastle And Newcastle With Gumboro}
Abdel Ameer H.Zahid
Nawal Salih Jafer
Anton S.AL- Bana
Pathology Dep.
Pathology Dep.
Microbiology Dep.

Coll.of Vet.Med.Baghdad University

\section{Summary}

This study is considered the first trail study in our country to apply In ovovaccination to immunize chicks against avian viral diseases. This method was conducted by using 150 chick embryos classified into three equal groups (50 embryo each group). The first group was inoculated with Newcastle disease virus-NDV (B1-strain). Second group was vaccineted with NDV. and GV( Gambaro virus). All vaccinated groups were inoculated in the amniotic sac, the 
third group (control group) was inoculated with sterile phosphate buffered saline. Result should the both vaccine did not reveal any negative effect on the percentage of hatchability and liaviability of the vaccinated chicks.

Hemagglutination inhibition (HI), ELISA and challenge test were used to evaluate the level of immunity in chicks vaccinated with (NDV.) alone and (GV.) \& (NDV.) double vaccine beside the control group chicks. The result revealed in spite of lower level of mean antibody titer of HI and ELISA in age of 28 days the two vaccinated group were resistant to challenge with virulent NDV. with $60 \%$ mortality rate in the control group.

\section{المقدمة}

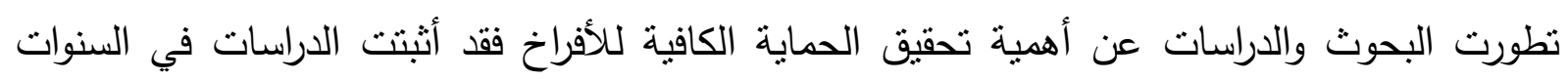

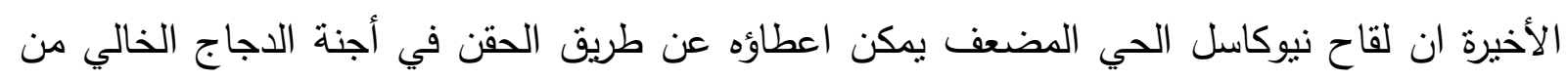

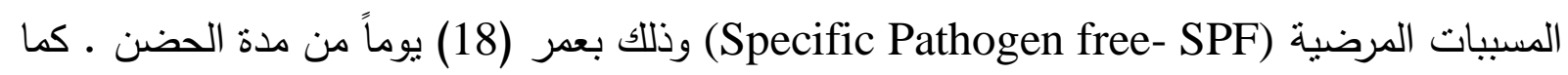

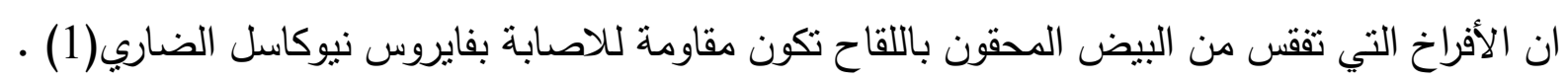

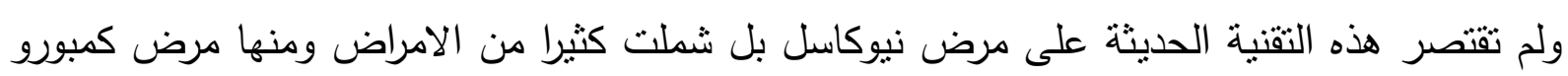

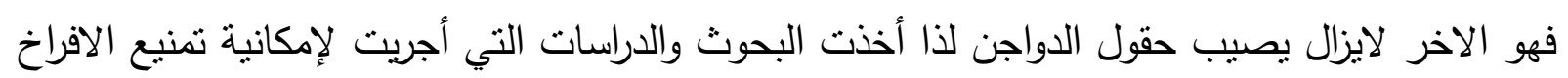

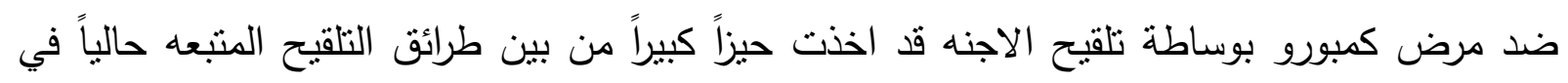

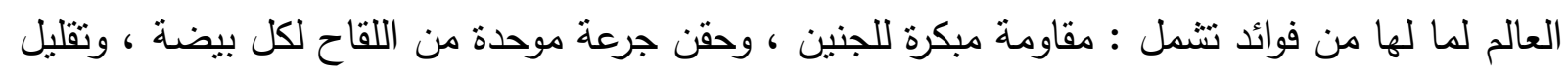
الكلفة والجها مع قلة التلوث (2). ونظراً لما حققته هذه البحوث والدراسات من نجاح هذه الطريقة على الامراض الفايروسية المهمة في

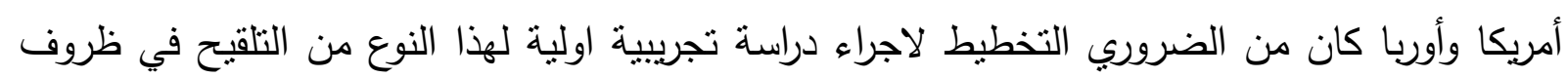

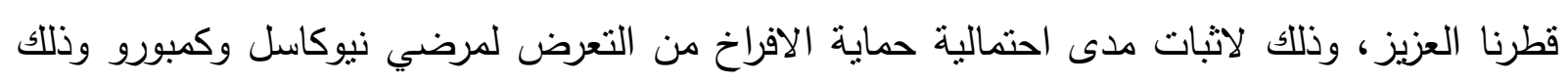

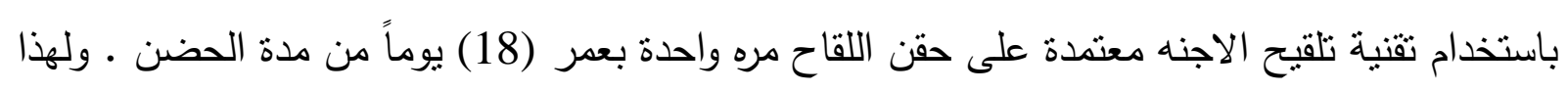

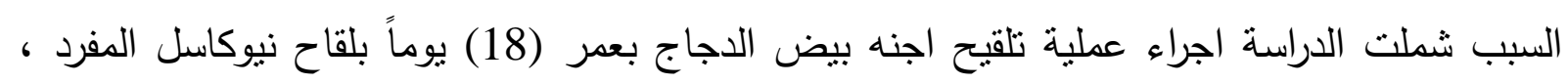

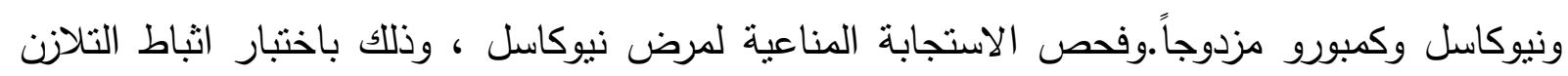
الادوي ، واختبار الاليزا ، واختبار التحدي. 


\section{المواد وطرائق العمل}

اجري البحث في كلية الطب البيطري / جامعة بغداد للمدة من 2/1 لغاية 3/20 /2001 من اجل تقييم

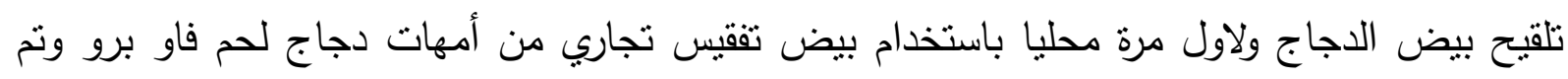

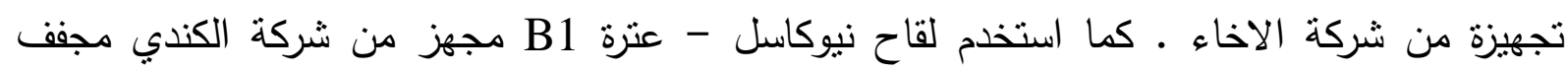
(Lyphoilized)

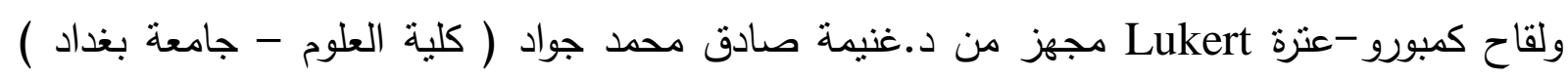

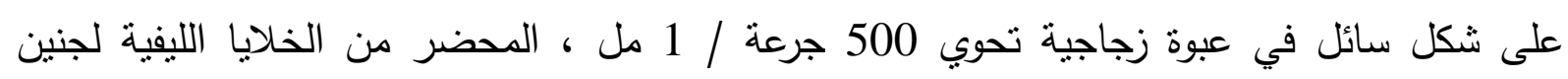

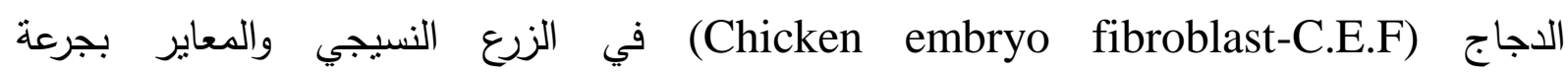
(103TCID50) dose) مساعد / كلية الطب البيطري / جامعة الموصل. حضن البيض:تم حضن 150 بيضة مخصبة في الحاضنة حتى حين البن التفقيس بعمر 18 يوماً من مدة الحضن ونم تقسيمها الى ثناتث مجاميع منساوية . طريقة حقن البيض :تم حقن البيض المخصب بعمر (18) يوماً من مدة الحضن بعد التأكد من حيوية

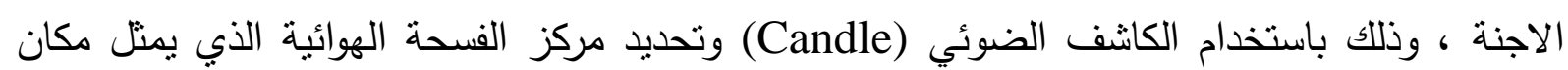
الحقن حسب طريقة (3) وتعقم منطقة الفسحة الهوائية بمحلول اليود (Germ Iodine) وتثقب قثترة البيضة بثاقبة ومن ثم حقن اللقاح بمقدار (0.1) مل باستخدام محقنة طبية بسعة (1) ملثة (25) مل وابرة بطول

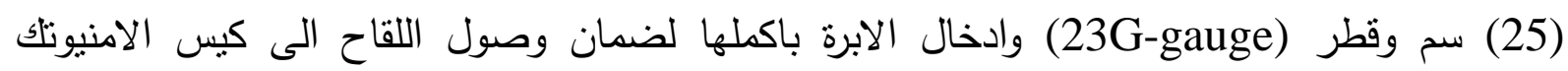

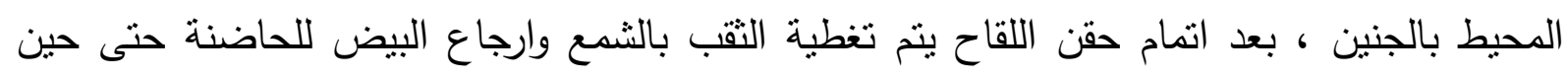
الفقس.

ولاجل ذللك تم اجراء تصميم دراسة تجربة تلقيح أجنة الدجاج بلقاحي نيوكاسل وكمبورو بما يأتي :

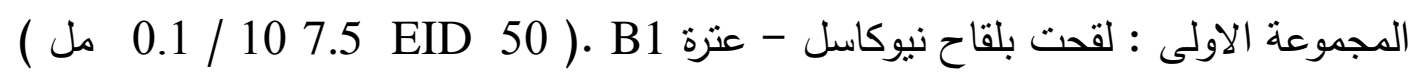
المجموعة الثانية : لقحت بلقاحي نيوكاسل وكمبورو - عترة (0.1/10 4 TCID 50). Lukert المجموعة الثالثة : حقتت بمحلول دارئ الفوسفات المعقم. مكان التربية :بعد فقس البيض نقلت الأفراخ الى وحدة نربية الدواجن في كلية الطب البيطري مع تهيئة

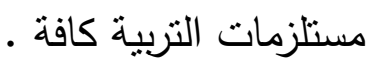


معايرة لقاح نيوكاسل:تمت معايرة لقاح نيوكاسل باستخدام اجنة دجاج بعمر (9) أيام لمعرفة الجرعة

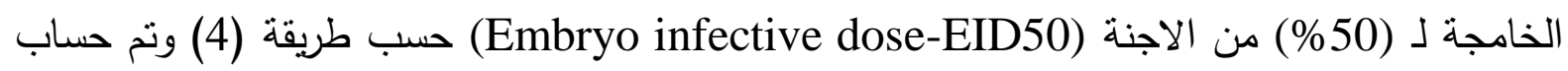
الجرعة الخامجه لـ (50\%) من الاجنة حسب طريقة (5) من الاجة معايرة فايروس نيوكاسل الضاري :تمت معايرة

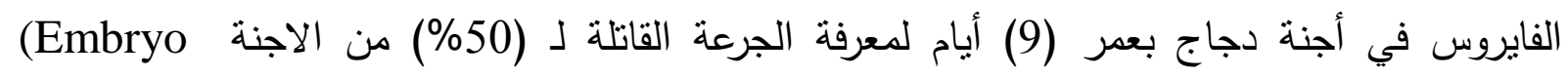
Lethal dose-ELD50)

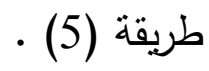

حساب نسبة الفقس : تم حساب نسبة الفقس للمجاميع الثلاث كافة ، وذللك باستخراج النسبة المئوية لكل

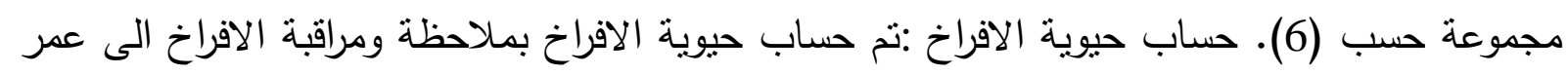
(7) أيام بعد الفقس وتسجيل الحالات الهالكة حسب (1). اختبار التنازن الدموي : استخدمت العترة اللقاحية La Sota لاجراء هذا الفحص حسب طريقة (7). اختبار نتثيط التنازن الدموي : نم أجراء

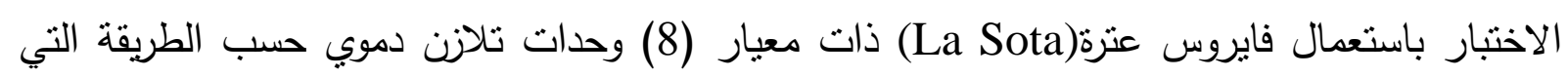
ذكرها (7). جمع عينات الدم وفصل المصل: سحبت عينات الدم من الافراخ عشوائياً بمعدل 15 عينة لكل مجموعة . اختبار التحدي: تم إعطاء فايروس نيوكاسل الضاري ذي معيار 0LD50 0.1/107.4 مل بمقدار (0.2) مل بالتقطير بالمنخرين ، العين والفم لكل طير وللمجاميع كافة وبعمر ( 28) يوماً وتمت ملاحظة التهاري

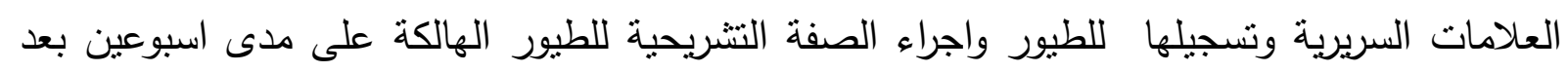

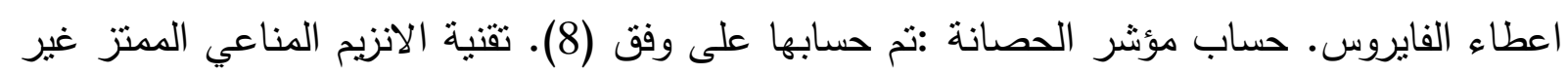

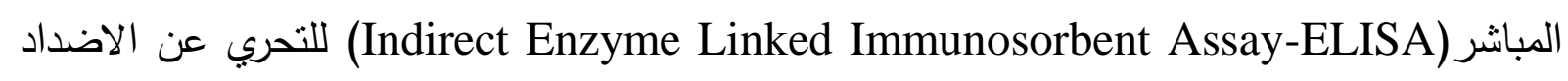
الخاصة لمرض نيوكاسل ، وأجري الفحص بإنباع التعليمات الموصى بها من المختبر المنتج للعدة الاضدي

التحليلات الإحصائية : استخدم تحليل التباين (Analysis of Variance) وفحص (F-test) لبيان

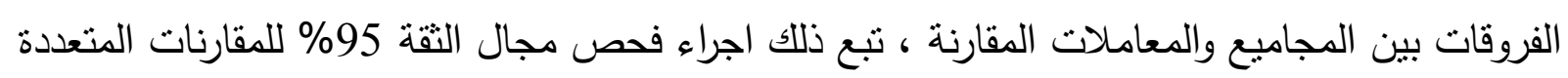
وفحص اصغر فرق معنوي (5\% و 1\% ) لغرض تحديد مواقع الاختلافات بين معدلات المعاملات

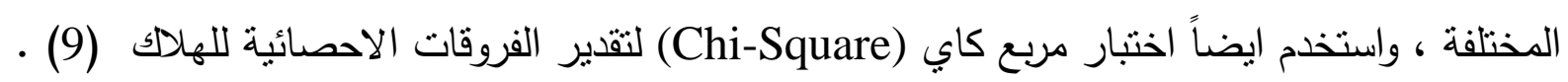

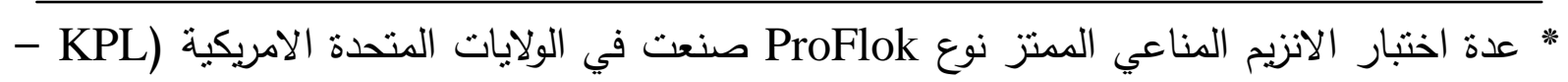
(Kirkegaard and Perry Laboratories 
النتائج

نسبة الفقس في الأجنة الملقحة: اظهرت نتائج الأجنة للمجموعتين الملقحتين المختلفة نسبة فقس واحدة

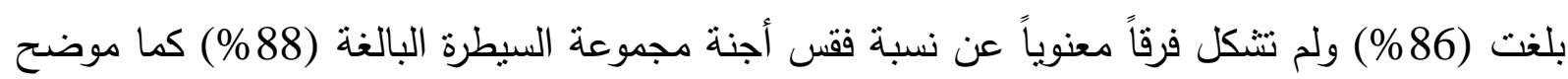

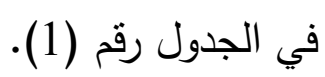

الجدول (1) تأثير اللقاح على نسبة فقس الأجنة عند تلقيحها بعمر (18) يوماً

\begin{tabular}{|c|c|c|c|c|}
\hline 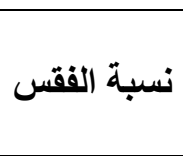 & الأمحقة الفاقة / عدد الأجنة & الجرعة & نوع اللقاح & المجاميع \\
\hline$\% 86 a^{* *}$ & $43 / 50$ & 107.5EID50 & * لقحت بلقاح نيوكاسل (عترة - B1) & المجموعة \\
\hline$\% 86 a$ & $43 / 50$ & $\begin{array}{l}\text { (ND) } \\
\text { 107.5EID50 } \\
\text { (IBD)104 } \\
\text { TCID50 }\end{array}$ & $\begin{array}{l}\text { لقحت بلقاحي نيوكاسل وكمبورو معاً } \\
\text { (B1- Lukert) }\end{array}$ & الثجموعة الثانية \\
\hline$\% 88 a$ & $44 / 50$ & - & حقتت بمحلول دارئ الفوسفات المعقم & الثبالثة \\
\hline
\end{tabular}

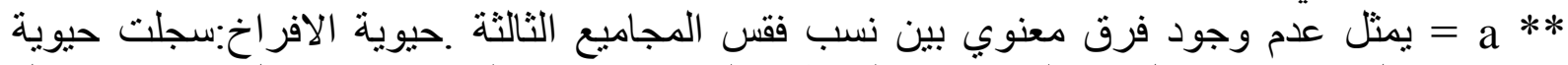

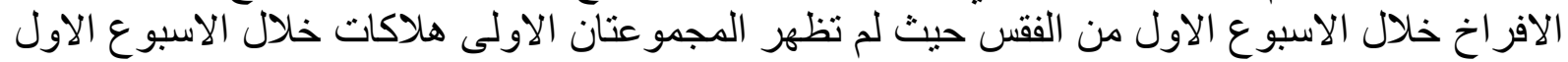

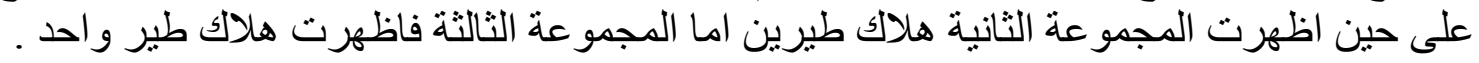

نتائج معيار اضداد مرض نيوكاسل:سجلت النتائج وذللك باجراء اختبار اثباط التلازن الدموي (HI) واختبار الاليزا (ELISA) وبما يأني:

نتائج اختبار اثباط التلازن الدموي:اظهر تحليل التباين وفحص FA الإحصائي وجود فروقات معنوية

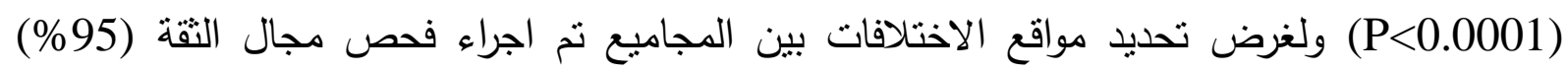

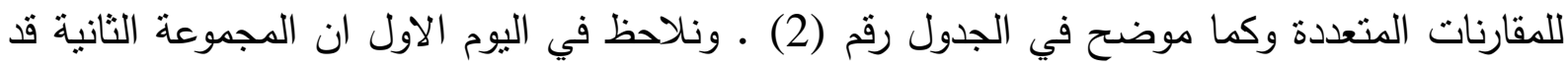
اظهرت معدل اضداد منخفض بفرق معنوي قدره (P<0.05) عن المجموعة الثانية (الملقحة نيوكاسل) اما لمان

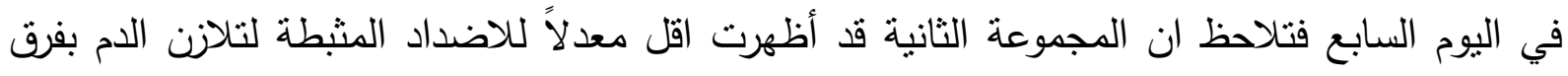
معنوي قدره (P<0.05) عن المجموعتين الثانية والسيطرة.

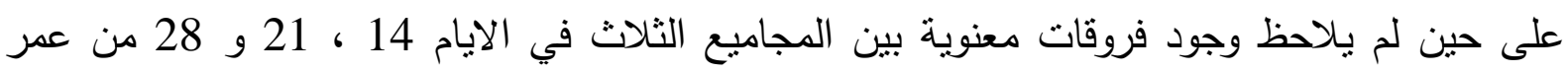

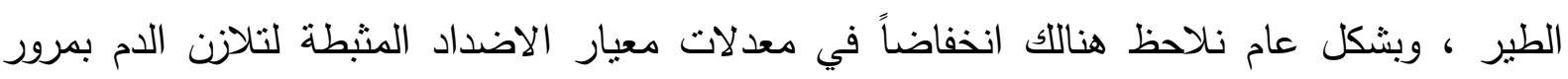
الوقت وللمجاميع الثناث. 
المجلة الطبية البيطرية العراقية ، المجلد 29 ، العدد 2 ، السنة 2005

الجدول (2) نتائج اختبار اثباط التلازن الدموي لفايروس مرض نيوكاسل

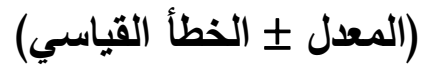

\begin{tabular}{|c|c|c|c|c|c|}
\hline 28 & 21 & 14 & 7 & 1 & العمر بالايام \\
\hline $3.20 \mathrm{a}$ & $2.70 \mathrm{a}$ & $3.75 \mathrm{a}$ & $67.2 \mathrm{a}$ & $56.5 \mathrm{ab}$ & \multirow{2}{*}{ المجموعة الاولى (ملقحة نيوكاسل) } \\
\hline $0.61 \pm$ & $0.64 \pm$ & $0.85 \pm$ & $10.2 \pm$ & $12.3 \pm$ & \\
\hline $2.20 \mathrm{a}$ & $4.33 \mathrm{a}$ & $9.53 \mathrm{a}$ & $7.29 \mathrm{~b}$ & $34.0 \mathrm{ac}$ & \multirow[t]{2}{*}{ المجموعة الثانية (ملقحة نيوكاسل وكمبورو) } \\
\hline $0.46 \pm$ & $0.54 \pm$ & $2.31 \pm$ & $2.18 \pm$ & $9.01 \pm$ & \\
\hline $1.55 \mathrm{a}$ & $0.25 \mathrm{a}$ & $9.41 \mathrm{a}$ & $52.1 \mathrm{a}$ & $40.5 a^{*}$ & \multirow[t]{2}{*}{ المجموعة الثالثة (سيطرة) } \\
\hline $0.93 \pm$ & $0.17 \pm$ & $1.6 \pm$ & $12.3 \pm$ & $8.03 \pm$ & \\
\hline
\end{tabular}

(الفرق بين المعدلات التي تحمل حروفاً مختلفة مهمة إحصائيا بنسبة (P<0.05)

نتائج اختبار الاليزا :اظهر تحليل التباين وفحص F الاحصائي وجود فروقات معنوية (P<0.0001)

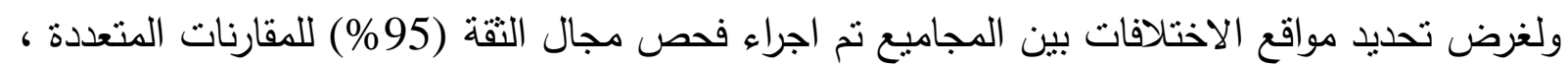
وكما هو موضح في الجدول رقم (3) حيث نلاحظ في اليوم الاول والسابع ارتفاع معدلات اقيام الكثافة

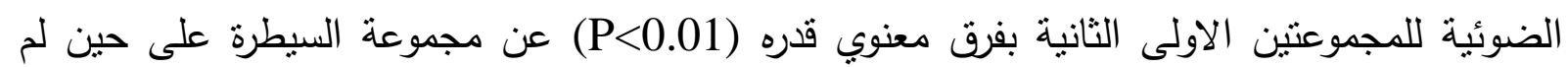

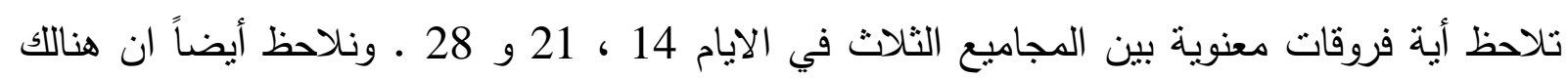

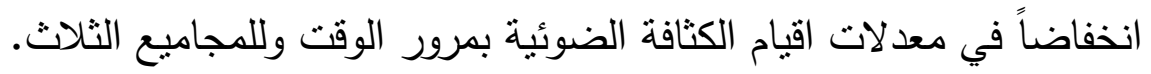

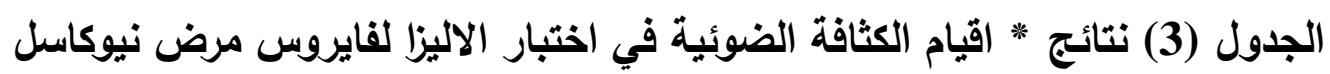

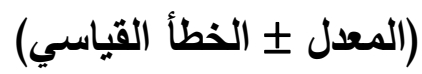

\begin{tabular}{|c|c|c|c|c|c|}
\hline 28 & 21 & 14 & 7 & 1 & العمر بالأيام \\
\hline $0.07 \mathrm{a}$ & $0.08 \mathrm{a}$ & $0.11 \mathrm{a}$ & $0.17 \mathrm{~b}$ & $0.41 b$ & المجموعة الاولى (ملقحة بنيو كاسل) \\
\hline $0.008 \pm$ & $0.006 \pm$ & $0.01 \pm$ & $0.01 \pm$ & $0.02 \pm$ & \\
\hline $0.10 \mathrm{a}$ & $0.09 \mathrm{a}$ & $0.12 \mathrm{a}$ & $0.19 \mathrm{~b}$ & $0.43 b$ & المجمو عة الثانية (ملقحة بنيو كاسل \\
\hline $0.01 \pm$ & $0.008 \pm$ & $0.009 \pm$ & $0.01 \pm$ & $0.06 \pm$ & وكمبورو) \\
\hline $0.11 \mathrm{a}$ & $0.07 \mathrm{a}$ & $0.11 \mathrm{a}$ & $0.10 \mathrm{a}$ & $0.28 \mathrm{a}^{* *}$ & المجموعة الثالثة (سيطرة) \\
\hline $0.02 \pm$ & $0.004 \pm$ & $0.009 \pm$ & $10.03 \pm$ & $0.02 \pm$ & \\
\hline
\end{tabular}

Optical density = OD * ** الفرق بين المعدلات التي تحمل حروفاً مختلفة مهم احصائياً نسبته (P<0.01) . 
نتائج اختبار التحدي بفايروس نيوكاسل الضاري :سجلت نتائج اختبار التحدي بملاحظة الافراخ مدة

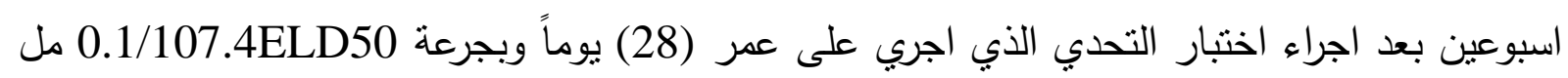

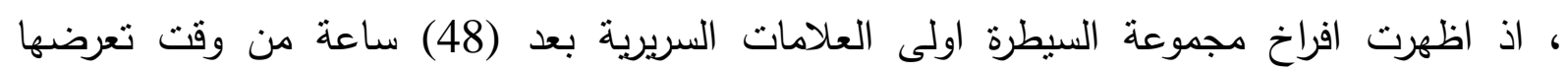

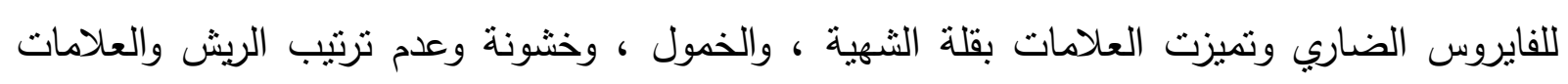

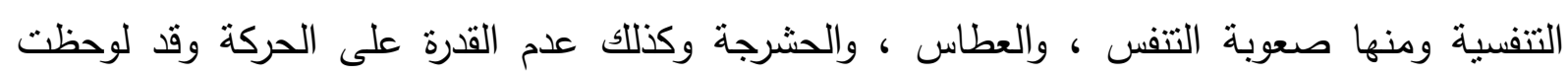

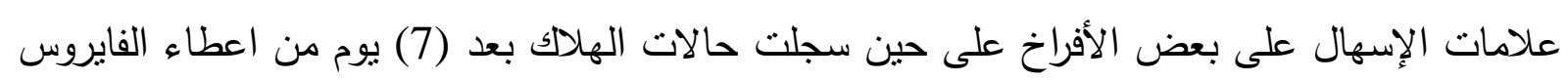

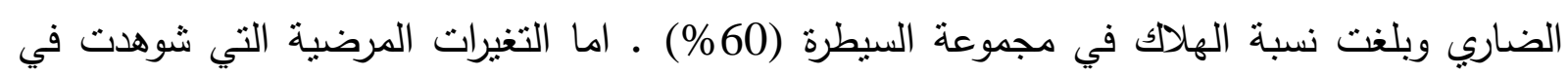

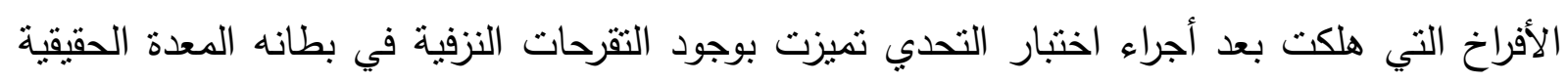

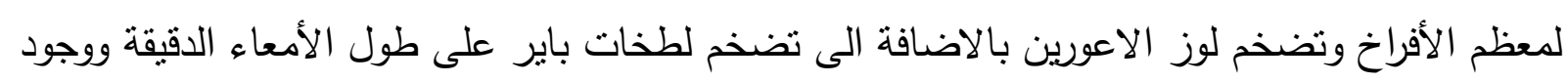
نتخر وتقرح على بعض منها. على حين شملت التغيرات المرضية التتفسية وجود بعض المواد المخاطية في القصبة الهوائية واحتقانها

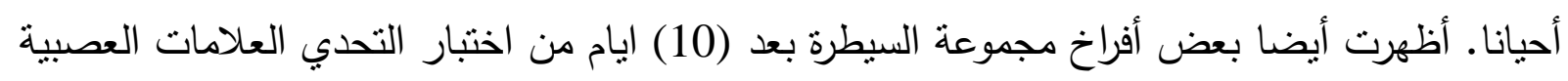

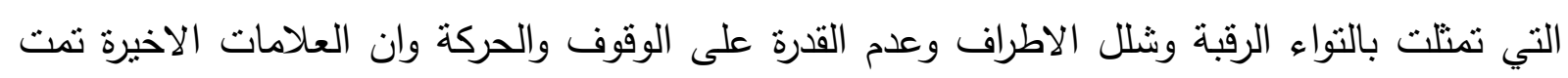

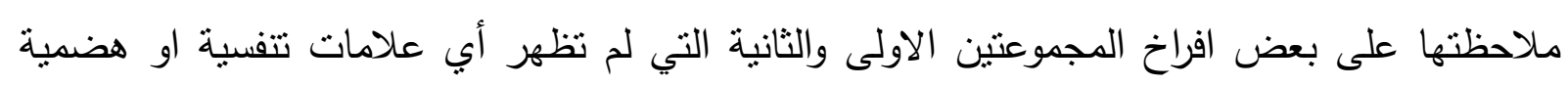

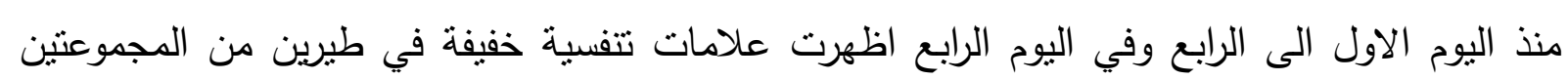

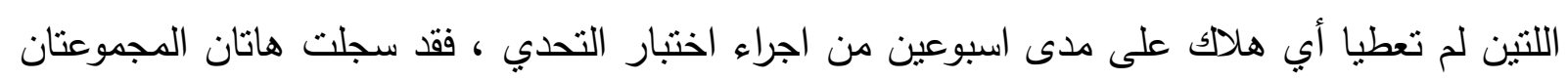

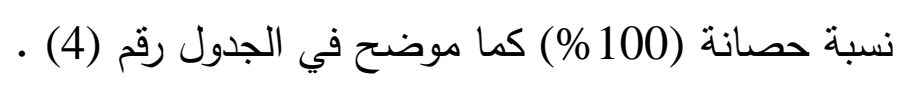

\section{الجدول (4) نتائج اختبار اثباط التلازن الدموي وإختبار التحدي لمجاميع الافراخ الملقحة جنينياً}

\begin{tabular}{|c|c|c|c|}
\hline الحصبة & عدد الهالاكات & الموجبة لاختبار اثباط التلازن الدموي العينات العينات & المجاميع \\
\hline$\% 100$ & $0 / 15$ & (3.20) $10 / 10$ & (ملقحة نيوكاسل) المجوعة الاولى \\
\hline$\% 100$ & $0 / 15$ & (2.20) $8 / 10$ & (ملقحة بنيوكاسل وكمبورور) \\
\hline$\% 40$ & $9 / 15$ & $(1.55) * 3 / 10$ & المجموعة الثالثة (السيطرة) \\
\hline
\end{tabular}

* العدد بين قوسين يمثل معدل أضداد اختبار اثباط التلازن الدموي بعمر (28) يوماً قبل اختبار التحدي. 


\section{المناقشة}

تعد الدراسة في طريقة تلقيح أجنة الدجاج ضد مرضي نيوكاسل وكمبورو الاولى من نوعها في القطر ، اذ تهدف الدراسة الى معرفة نأثير لقاح نيوكاسل الحي (عنرة - B1) ولقاحي نيوكاسل فئل وكمبورو المزدوج

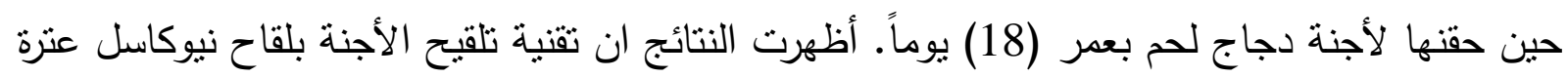

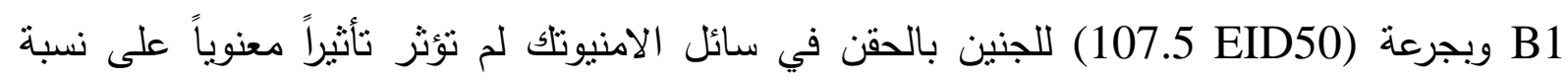

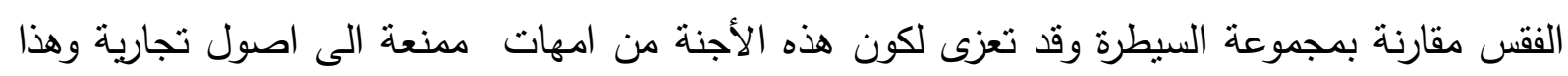

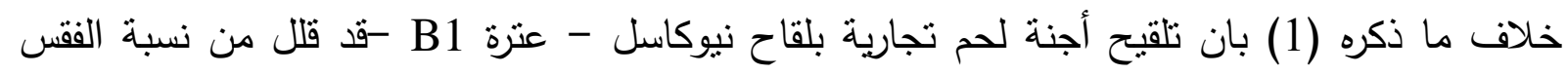

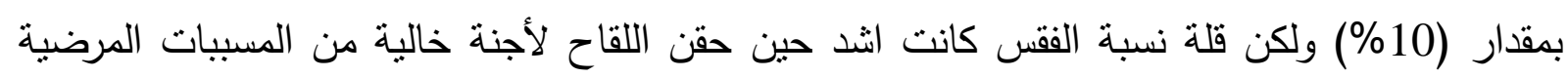

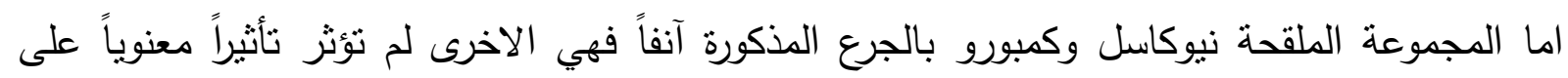
نسبة الفقس مقارنة بمجموعة السيطرة على خلاف ما اثشار اليه الباحثون (10) بان تلقيح أجنة دجاج لهاج

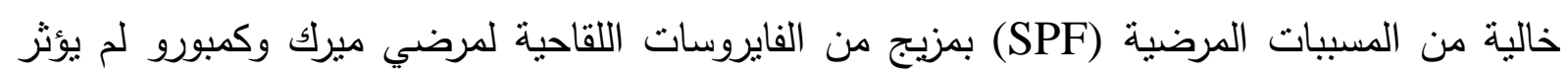

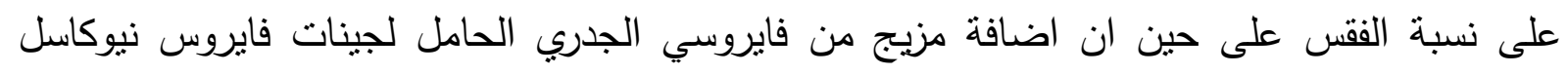
(rFP - NDV)

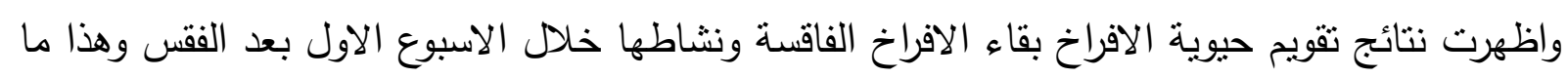

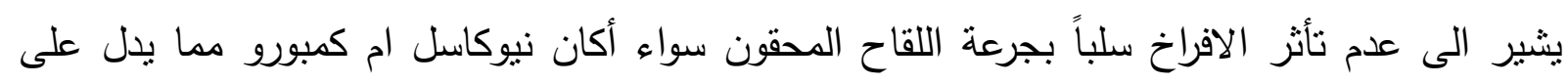

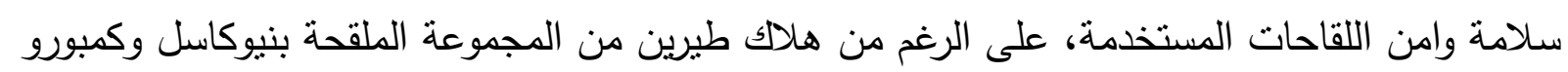

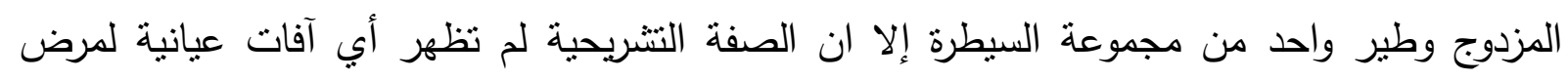
كمبورو او نيوكاسل .

اما بالنسبة لنتائج معدل معيار الأضداد المثبطة لتلازن الدم للمجاميع الثلاث : الملقحة بنيوكاسل ،

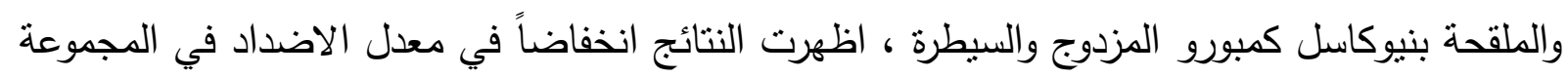

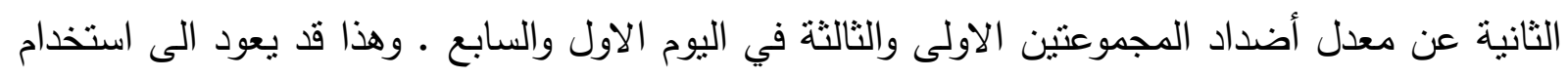

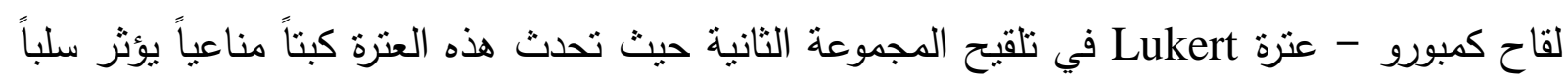

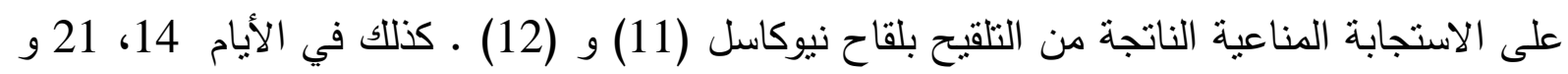

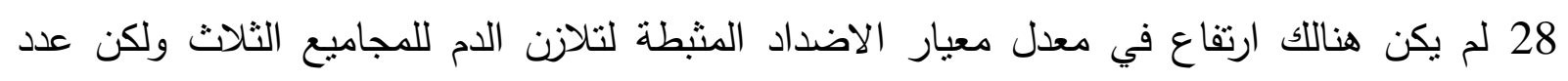

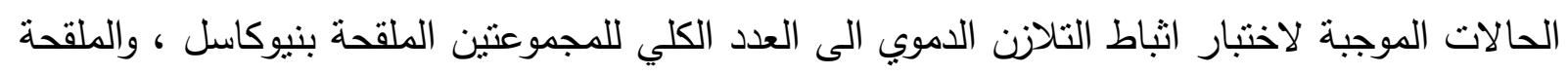

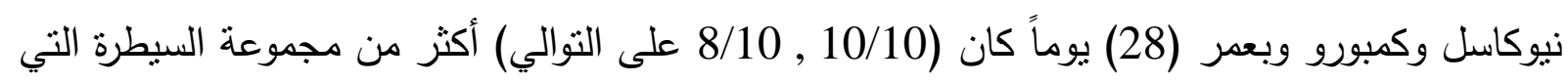
أعطت (3/10) راجع الجدول رقم (4) ، وهذا ما اثنار اليه الباحثان (13) في اعتماد هذا المقياس 


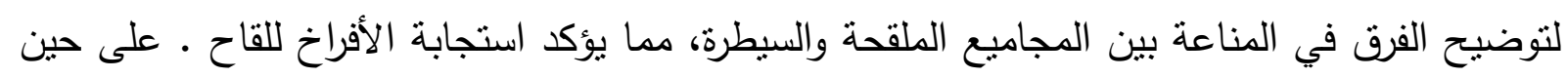

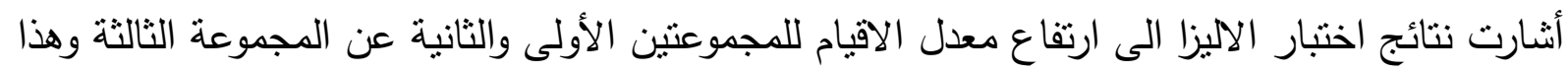

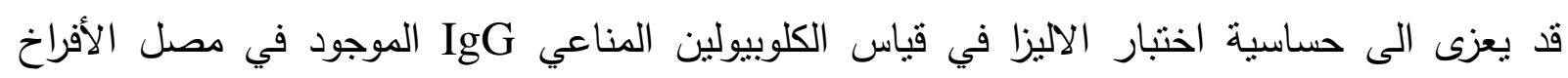

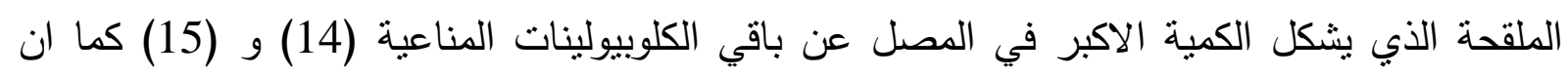
المصل الممنع المستخدم في عدة الاختبار للكثف عن أضداد النيوكاسل متخصص لقياس الكئل الكلوبيولين

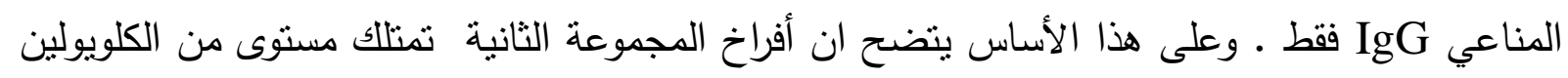

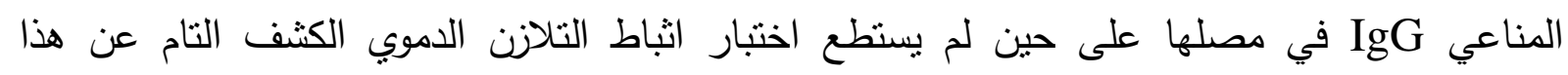

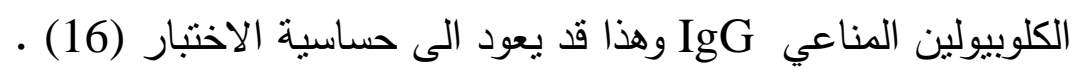

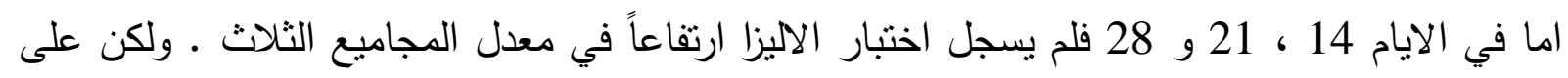

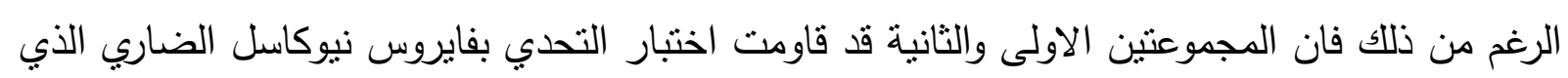

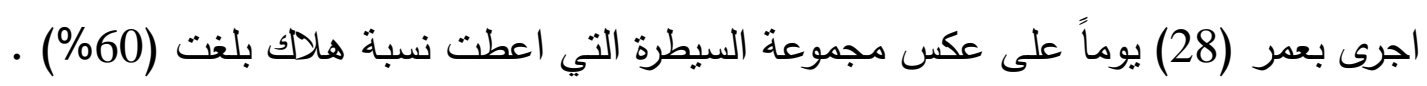
ويمكن تفسير مقاومة المجموعتين الملقحتين لاختبار التحدي بالاسباب الآتية:

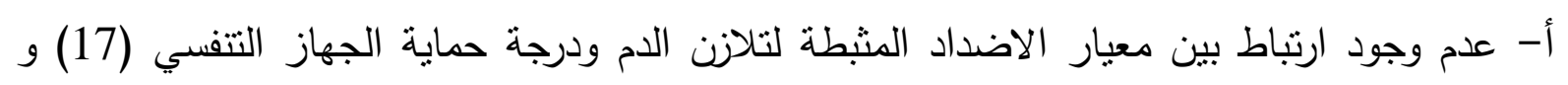
(18) و (19) فقد اظهرت الدراسات ان مقاومة القناة التنفسية للاصابة بفايروس نيوكاسل لا لا يرتبط

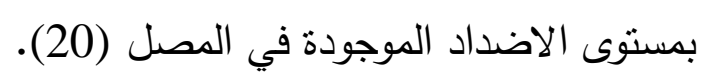
ب- فضلاً عن وجود المناعة الخلوية التي تحقق الحماية ضد الاصدابات الفايروسية في الطيور الممنعة التي لا تمنلك مستويات ملحوظة من الاضداد المثبطة لتلازن الدم (21).

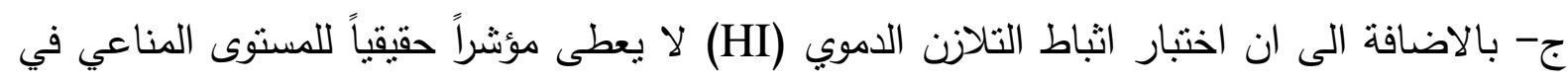

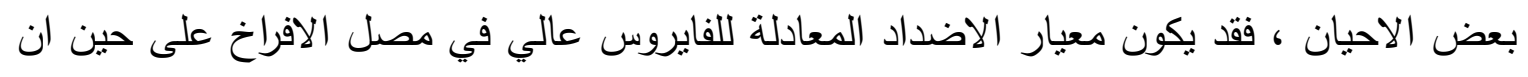

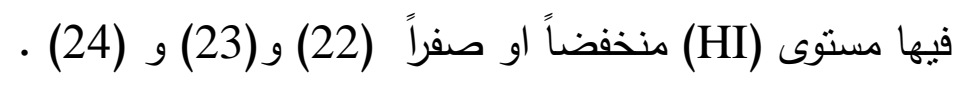
د- وقد تعزى حماية هذه المجموعنين ضد التعرض للاصابة بفايروس نيوكاسل الضاري الى طريقة

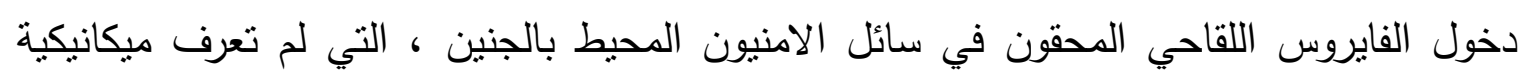
عمل هذا اللقاح ، ولكن يعتقد ان أخذ فايروس اللقاح يكون عن طريق استتشاق او ابتلاع السائل

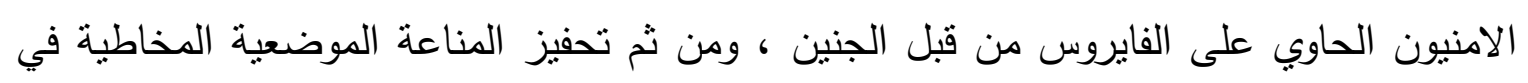

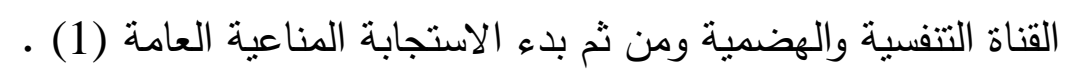

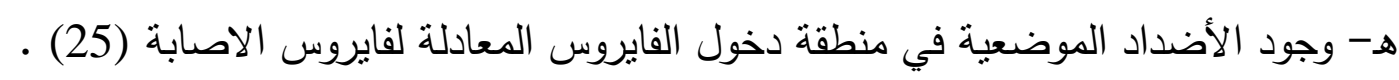
تتفق هذه التفسيرات وما انشار البه (22) من ان نسبة الحصانة تتتاسب مع مستوى الاضداد في القصبة

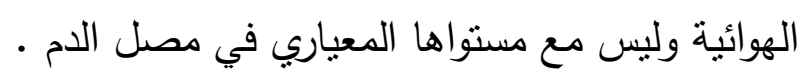


ان استخدام اختبار التحدي فضلا عن قياس مستوى الأضداد المنبطة للتلازن الدموي (HI) لغرض تقدير

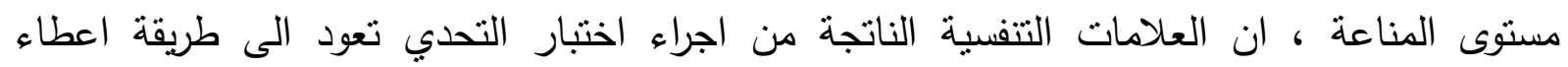

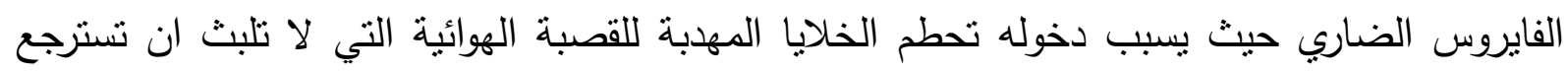
بناءها خلال مدة قصيرة وقد تطول الى عشرة ايام حيث تختفي العلامات التنفسية وهذا يتفق وتفسير

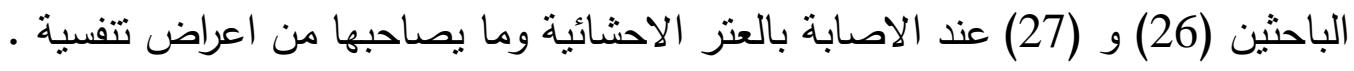

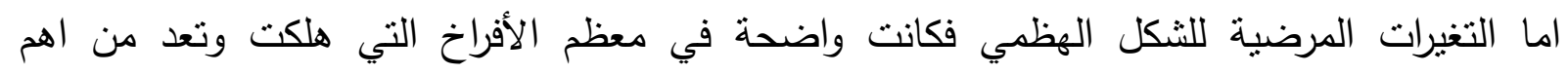
التغييرات المرضية التي يحدثها فايروس مرض نيوكاسل الضاري المنتشر في منطقة آسيا (27) و (28)

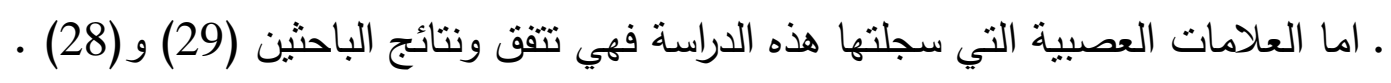

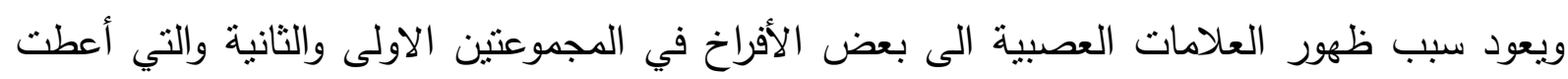

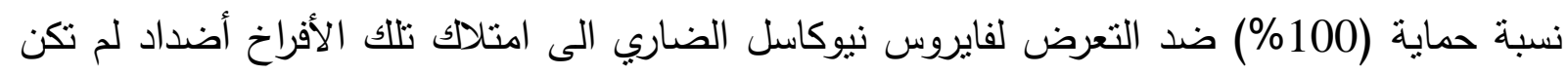

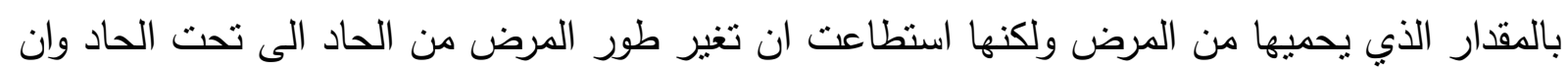

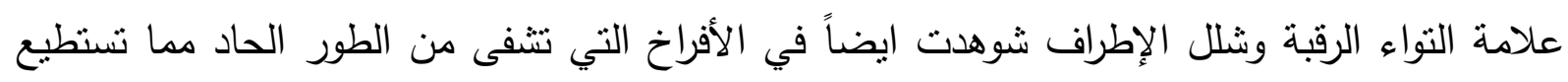

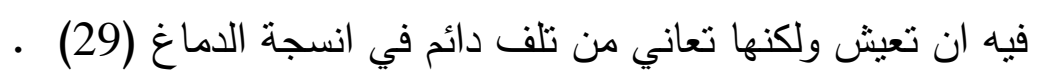
وقد اعطت نتائج اختبار التحدي بفايروس نيوكاسل الضاري للمجموعة الملقحة نيوكاسل وكمبورو نسبة حصانة بلغت (100\%) وهذه النتيجة بينت عدم وجود اثباط مناعي بلقاح كمبورو للاستجابة المناعية ضد مرض نيوكاسل .

نستتنج من ذلك ألمكانية تطبيق طريقة تلقيح أجنة الدجاج من اصول تجاربة ضد مرض نيوكاسل لما

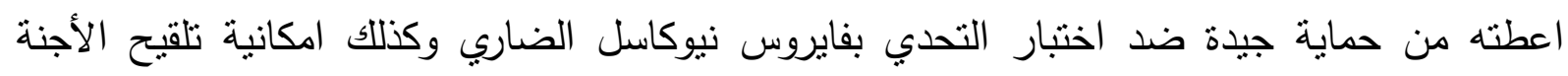

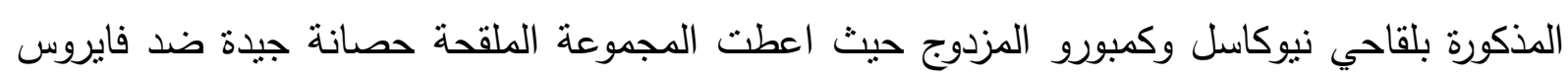

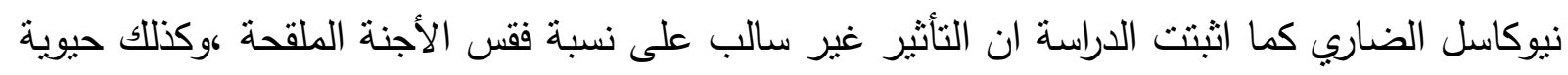

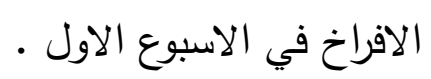

\section{References}

1. Ahmad, J and Sharma , J.M. (1993). Protection against hemorrhagic enteritis and Newcastle disease in turkeys by embryo vaccination with monovalent and bivalent disease. Avian Dis. 37: 485-491.

2. Ricks, C.A.; Avakian, A.; Bryan, T.; Gildersleeve, r.; Haddad, E.; Ilich, R.; King, S.; Murray, L.; Phelps, P. Poston, R.; Whitfill, C. and Wiliams, C. (1999). Inovo vaccination technology. Adv. In Vet. Med. 41:495-515.

3. Sharma, J. M. and Burmester, B.R. (1982). Resistance to Marek's disease at hatching in chickens vaccinated as embryos with the turkey herpes virus. Avian Dis .26:134-149. 
4. Allan, W. H.; Lancaster, J. E. and Toth, B. (1978). "Newcastle disease Vaccines their production and use" Food and Agriculture organization of the united nation, Rome.

5. Reed, L. J. and Muench, H. (1938). A simple method of estimating fifty percent and points. Am. J. Hyg. 27: 493-497.

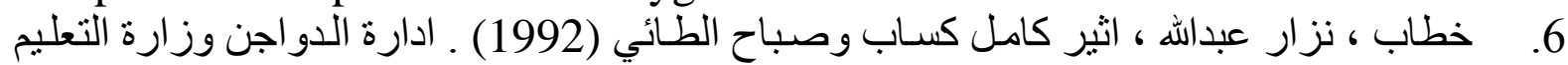

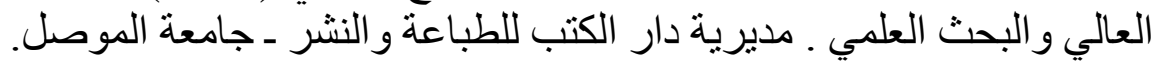

7. Hanson, R. P. (1980). Newcastle disease. In: "Isolation and identification of avian pathogen". Hitchner, S. B.; Domermu, H. C.; Purchase, H. G. and William , J. E. Eds. 2nd ed. American Association of Avian Pathologists. USA. PP.36-66.

8. Jackson, C.; Lehrbach, P. R.; Whitfill, C. E. and Cheetle , N. (1997). Developments in the Vaccination of broiler chickens and larger pullets againts infectious bursal disease. In: Proc. Australian poultry scince symposium, Vol. 9. P.103.

9. المحمد ، نعيم ثاني ، خاشع محمد الر اوي ، مؤيد يونس ووليد المر اني (1986) ـ ـ مبادئ الاحصـاء

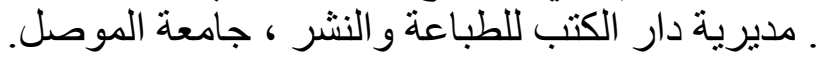

10. Gagic, M.; Hill, C. a. and Sharma, J. m. (1999). Inovo vaccination of specific - pathogen- free chicken with vaccines containing multiple agents. Avian Dis. 43:293-01.

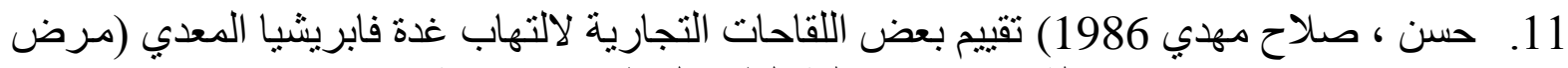

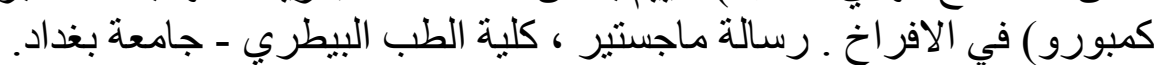

12. Khan, S. Z.; Mushtaq, A.; Ayaz , m. and Raziq , E. (1998). Immunosuppressive effect of four different Gumboro vaccine strain on HI antibody titer against Newcastle disease vaccine in broiler. Sarhad. J. Agric. 14:1-3.

13. Ahmad, J. and Sharma, J.M. (1992). Evaluation of a modified-live virus vaccine administered in ovo to protect chicken against Newcastle disease. Am. J. Vet. Res. 53:1999-2004.

14. Powell, J. R. (1982). The immune system B- cells and T- cells. In: "Avian Immunology" Powell, J. R. Ed. British Veterinary Poultry association. PP.7-15.

15. Higgins, D. A. (1996). Comparative immunology of avian species. In: "Poultry Immunology". Davison , T. F.; Morris, T. R. and Panyne , L. N. Eds. Jr. 1st Ed. Oxford, U.K. PP.149-205.

16. Snyder, D.B.; Marquardt, W.W.; Mallinson, E.T. and Russek, E. (1983). Rapid serological profilling by enzyme- linked immunosorbent assay. I. measurement of antibody activity titer against Newcastle disease virus in a single serum dilution. Avian Dis. 27;161-170. 
17. Knezevic, N. (1989). Comparative study of two vaccination methods employing Newcastle vaccines (Lasota strain) for passively immune chicken under laboratory conditions. Vet. Archive. 59:225-231.

18. Holmes, H. C. (1979a). virus - neutralizing antibody in sera and secretions of upper and lower respirators tract of chickens inoculated with live and inactivated Newcastle disease virus. J. Comp. Path. 89:21-29.

19. Knezevic, N.; dekic, J.; Krecov, M. and Kozlina, B. (1994). Comparative survey of different programmes of immunoprophylaxis against Newcastle disease in broiler chickens. Vet. Glasnik. 48:869-873.

20. Holmes, H. C. (1979b). Respirators tract of chickens to Newcastle disease virus infection following vaccination the effect of passively acquired antibody on its development. J. Comp. Path. 89:11-19.

21. Jayawardan, G. W. and Spradbrow, P. B. (1995). Cell - mediated immunity in chickens vaccinated with the V4 strain of Newcastle disease virus. Vet. Microbiol. 46:37-41.

22. Martin, S. F.; Mc Williams, M. and Huizenga, C. G. (1972). Use of chicken tracheal organ cultures for studying resistance of respiratory epithelium to viral infection. J. Immuno. 108:183-194.

23. حسين ، عبدالامير (1980) ـ دراسة في تقييم اللقاحات لمرض النيوكاسل المنتجة محلياً في افر اخ

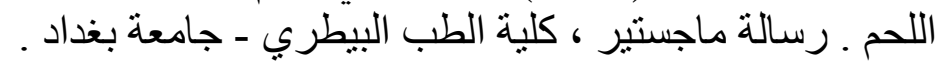

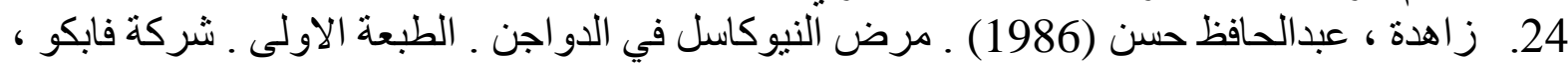

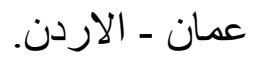

25. (25)Spanoghe, L.J.; Peeters, E.; Cotlear, J.C.; Doves, A.H. and Viane, N. (1977). Kinetics of serum and local heamagglutination inhibition antibodies in chicken following vaccination and experimental infection with Newcastle disease virus and their relation with immunity. Avian Pathol.6:101-109.

26. (26)Cheville, N.F.; Stone, H.; Riley, J. and Ritechic, A.E. (1972).

Pathogensis of virulent Newcastle disease chickens. J.Am. Vet. Ass. 161: 169-179.

27. Hanson, R. P. (1978). Newcastle disease. In: "Disease of poultry". Hofstad, M. S.; Calnek , B. W.; Helmbodt , C.F.; Reid , W. M. and Yoder , H. W.

Eds. 7th ed., Iowa state university press, Ames, Iowa, U.S.A. PP.668-671.

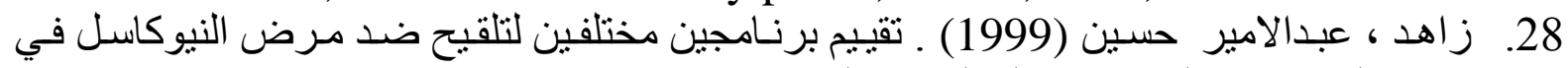
افر اخ البياض في العر اق ـ مجلة الطبيب البيطري

29. Al-Sheikly , F. and Carlson , M.C. (1975). The pathology of Velgenic Newcastle disease virus infection. Avian Dis. 19:397-407. 